\title{
The Effects of Intraoperative Sedation on Surgical Outcomes of Deep Brain Stimulation Surgery
}

\author{
Jason Chui, Rizq Alimiri, Andrew Parrent, Rosemary Ann Craen
}

\begin{abstract}
Background: Intraoperative sedation is often used to facilitate deep brain stimulation (DBS) surgery; however, these sedative agents also suppress microelectrode recordings (MER). To date, there have been no studies that have examined the effects of differing sedatives on surgical outcomes and the success of DBS surgery. Methods: We performed a retrospective study to evaluate the effect of differing sedative agents on postoperative surgical outcomes at 6 months in parkinsonian adult patients who underwent DBS surgery, from January 2004 through December 2014, at one academic center. Surgical outcomes of DBS were evaluated using a simplified Unified Parkinson Diseases Rating Score-III and levodopa dose equivalent reduction at baseline and 6 months postoperatively. Results: We analyzed data from 121 of 124 consecutive parkinsonian patients. Propofol, dexmedetomidine, remifentanil, and midazolam were used individually or in combination. All sedatives were routinely discontinued 20 to 30 minutes before MER, in accordance with our institutional protocol. We found no statistically significant association between the use of individual agent or combination of sedative agents and surgical outcomes at 6 months, the success of DBS, duration of MER, duration of stage 1 procedure, and perioperative complications. Conclusions: Our study showed that the choice of sedative agent was not associated with poor surgical outcomes after DBS surgery using MER and macrostimulation techniques in parkinsonian patients.
\end{abstract}

RÉSUMÉ: Les effets de la sédation peropératoire sur les résultats de l'intervention de stimulation cérébrale profonde. Contexte: La sédation peropératoire est souvent utilisée pour faciliter la technique chirurgicale de stimulation cérébrale profonde (SCP). Cependant, les sédatifs utilisés peuvent également supprimer les enregistrements des microélectrodes (EME). À ce jour, il n'existe pas d'étude examinant les effets de différents sédatifs sur les résultats de la chirurgie et le succès de la SCP. Méthodologie: Nous avons effectué une étude rétrospective afin d'évaluer l'effet de différents sédatifs sur les résultats postopératoires 6 mois après la chirurgie chez des patients adultes atteints de la maladie de Parkinson qui ont subi une chirurgie de SCP de janvier 2004 à décembre 2014 dans un centre universitaire. Les résultats chirurgicaux de la SCP ont été évalués au moyen d'une version simplifiée de l'UPDRS-III (échelle d'évaluation unifiée pour la maladie de Parkinson, partie III) et la diminution correspondante de la dose de lévodopa avant et 6 mois après la chirurgie. Résultats: Nous avons analysé les données de 121 parmi 124 patients parkinsoniens consécutifs. Le propofol, la dexmédétomidine, le rémifentanil et le midazolam ont été utilisés seuls ou en combinaison. Tous les sédatifs étaient habituellement cessés 20 à 30 minutes avant l'EME, conformément au protocole en vigueur dans notre institution. Nous n'avons pas observé d'association significative au point de vue statistique entre l'utilisation de l'un ou l'autre des sédatifs, utilisés seuls ou en combinaison, et les résultats chirurgicaux 6 mois après l'intervention, le succès de la SCP, la durée de l'EME, la durée de l'intervention de stade 1 et les complications périopératoires. Conclusions: Notre étude a montré que le choix de l'agent sédatif n'était pas associé à de mauvais résultats chirurgicaux après une chirurgie de SCP utilisant les techniques d'EME et de macrostimulation chez des parkinsoniens.

Key words: anesthesia, deep brain stimulation, dexmedetomidine, outcomes, Parkinson's disease, propofol, remifentanil, sedation

Deep brain stimulation (DBS) surgery has been increasingly used to treat medical refractory parkinsonian patients over the past two decades. ${ }^{1}$ Previous studies have shown DBS can improve motor symptoms, alleviate levodopa-related side effects, and generally improve the quality of life in Parkinson's disease (PD) patients. ${ }^{2}$ The major challenge in DBS is to accurately localize and insert the stimulating electrodes into targeted deep brain nuclei (e.g. subthalamic nuclei $[\mathrm{STN}])$. The most popular localization method is to use a combination of neuronavigation, microelectrode recording (MER), and macrostimulation ${ }^{3}$ in the awake, cooperative patient. More recently, image fusion alone to aide targeting of the deep brain nuclei has been used in patients under general anesthesia.

Intraoperative sedation is often used to improve patient comfort and facilitate MER and macrostimulation techniques; however, anesthetic agents such as propofol and dexmedetomidine, when used at sedative doses, can suppress electrophysiological activity in deep brain nuclei ${ }^{4-8}$ and thus interfere with MER localization. Because of this, sedative agents are not

From the Department of Anesthesia \& Perioperative Medicine (JC, AR, RAC) and Department of Clinical Neurological Sciences (Neurosurgery) (AP), Schulich School of Medicine and Dentistry, Western University, London, Ontario, Canada.

Received September 8, 2016. Final Revisions Submitted July 28, 2017. AcCePted August 30, 2017.

Correspondence to: Jason Chui, Department: Department of Anesthesia \& Perioperative Medicine, Institution, University Of Western Ontario, Canada, C3-106, University Hospital, 339 Windermere Road, London, Ontario, Canada N6A 5A5. Email: Jason. chui@lhsc.on.ca Address: Lawson Health Research Institute, 750 Baseline Road, East, Suite 300, London, Ontario N6C 2R5. 
used routinely in some centers. ${ }^{4-11}$ If sedation is used, drug infusions are usually stopped 20 to 30 minutes before localization to allow dissipation of drug.

In the late 1990s, our center performed DBS without using sedation. From 2004 onwards, we used intraoperative sedation to facilitate DBS. Several agents have been used, including midazolam, fentanyl, propofol, remifentanil, and, more recently, dexmedetomidine. Observational studies have reported the successful use of a single sedative agent during DBS. ${ }^{12-14}$ To date, there have been no studies that have examined the effects of differing sedatives on surgical outcomes and the success of DBS. The aim of this study was to evaluate the effects of differing sedative agents on surgical outcomes following DBS at our center.

\section{OBJECTIVES}

The primary objective was to examine the effect of each sedative agent (propofol, dexmedetomidine, remifentanil, or midazolam) on surgical outcome following DBS in parkinsonian patients at 6 months postoperatively. Our secondary objectives were to examine the association between each agent and the time taken to complete MER, the duration of the procedure, and the successful completion of the procedure. We also explored the types of the sedative regimen used (usually a combination of sedatives) and their effects on intraoperative and postoperative complications.

\section{METHODS}

\section{Study Design}

The study was approved by Lawson Health Research Institute, Western University (REB \#106592). This was a retrospective study. A predefined study protocol was developed (Figure 1). After obtaining approval, we retrieved the health record data of all PD patients who had undergone stage 1 DBS at University Hospital, London Health Sciences Centre, London, Ontario, Canada, between January 2004 and December 2014.

\section{Surgical and Anesthesia Techniques}

All patients were evaluated preoperatively by the anesthesia and surgery departments. On the day of surgery, a Leksell stereotactic frame was placed on the awake patient using local anesthetic infiltration at the pin sites only. A stereotactic magnetic resonance imaging scan, for surgical planning, was obtained before transfer to the operating room for stage I DBS procedure.

Standard monitoring, electrocardiograph, end-tidal carbon dioxide levels, pulse oximetry, and noninvasive and invasive blood pressure levels were measured. All patients received oxygen supplementation using nasal prongs. Sedation was administered at the discretion of anesthesiologist and titrated to patient comfort. All sedatives were stopped 20 to 30 minutes before MER commencement. A burr hole was created and MER was carried out with an array of five microelectrodes that were gradually advanced to and then beyond the target structure. The data from the MER trajectories were used to determine the boundaries of the STN (medial, lateral, anterior, posterior, superior) and suggested the likely therapeutic region of the STN as well as guiding the subsequent macroelectrode stimulation. The macroelectrode stimulation was carried out with the purpose of assessing therapeutic benefit (reduction of rigidity, when present), and stimulation side effect thresholds. If MER suggested that the electrode array was not optimally placed, the trajectory would be altered in the appropriate direction and repeated, followed by macroelectrode stimulation. If, at the time of MER assessment, neuronal units were not adequately seen, or were of very low amplitude, then generally the surgery was paused for an additional 20 to 30 minutes and reassessed if the MER quality improved. After a satisfactory trajectory was obtained, a DBS electrode (either 3389 or 3387 Medtronic, Minnesota, MN) was inserted. The electrodes were then secured and tunnelled.

\section{Data Source and Acquisition}

The list of all PD patients who had stage 1 DBS during the study period was provided by the neurosurgeons. Data were collected by reviewing all perioperative notes from the anesthesia, neurosurgery, and neurology departments, and intraoperative records from anesthesia, surgery, nursing, and intraoperative MER records from the neurophysiologists. All data were manually retrieved and verified before entry into predefined electronic data collection forms for analyses.

\section{Participants}

We included all adult patients (age $>18$ years of age) with PD, who had undergone DBS surgery in the study period. We did not include patients undergoing DBS for an indication other than PD, such as dystonia and essential tremor, because these patients have different clinical courses and outcome measures. We included patients who had unilateral or bilateral procedures with the target nuclei being STN and/or Globus Pallidus (GPi).

\section{Exposures and Ascertainments}

At our institute, there has never been a standard protocol for sedation. Choice of the sedative agent(s) and dosing was left to the attending anesthesiologist. Our neurosurgeons, however, requested that sedation be stopped 20 to 30 minutes before commencing MER. Data on the type and dosing of sedative agents used intraoperatively were obtained from the anesthesia records.

\section{Outcomes Measures and Ascertainments}

Primary surgical outcomes were quantified by the changes in the simplified Unified Parkinson Disease Rating Score-III (UPDRS-III) and by the changes in levodopa dose-equivalent (LEDD) reduction, from preoperatively (baseline) and at 6 months postoperatively. Both outcome measures are commonly used to assess the success of DBS in PD patients. ${ }^{15}$ Patient assessment at the 6-month period postoperatively is typically performed to allow for the full effect of neuromodulation. The UPDRS-III scoring system is a 108-point scale (assessing 18 motor symptoms), in which a lower score represents fewer motor symptoms. At our institute, the full UPDRS-III scoring system is not routinely used. Instead, a simplified version using 15 motor symptoms (a 76-point scale) is used. These symptoms include speech, facial expression, rigidity, finger tapping, hand movement, pronation, and supination movement of hand, toe-tapping, leg agility, arising from chair, gait, freezing of gait, postural stability, posture, body bradykinesia, and postural tremor of hands. Preoperative simplified UPDRS-III scores were performed at the medication-on state, whereas the 6-month postoperative scores were performed at medication-off, stimulation-on state. The LEDD \% reduction was 
obtained using the formula: (preoperative LEDD - postoperative LEDD)/preoperative LEDD $\times 100 \%{ }^{1}$

For the secondary outcomes, we measured the time periods; these were time taken to complete MER (retrieved from the neurophysiologist's records), duration of the stage 1 DBS procedure, duration of successful completion of the procedure, and duration of hospital stay. Time taken to complete MER for bilateral DBS was the sum of the time taken for each MER. The duration of the stage 1 DBS implantation procedure did not include the duration of stage 2 (the insertion of pulse generator). Stage 2 DBS procedures were performed under general anesthesia and, in some patients, stage II was performed on a different operative date.

All intraoperative and postoperative complications were identified by reviewing the intraoperative and postoperative anesthetic and surgical records. Intraoperative complications were classified into anesthesia- and surgical-related, whereas postoperative complications were classified into cognitive/psychiatric, procedural-related, physical-, and transient/permanent-related using the categories described in a previous DBS study. ${ }^{1}$

\section{Statistical Analyses}

Data were analyzed, and outliners were verified before statistical analyses. The Statistical Package for the Social Sciences (SPSS, version 20) was used according to the predefined plan. Demographics, medical, surgical, and anesthetic data were summarized as mean and standard deviation for continuous data and number (proportion) of nominal data. The Kolmogorov-Smirnov test was used to test for normality. Parametric data were tested by analysis of variance, the Kruskal-Wallis test was used for ordinal data, and categorical data were tested by the chi-square test. A p value $<0.05$ was considered significant.

We performed univariate and multivariate regression analyses to assess whether each agent had an effect on the following: surgical outcome at 6 months, time taken to complete MER, duration of the procedure, and successful completion of the procedure. Four sedative agent variables (propofol infusion [yes or no], dexmedetomidine infusion [yes or no], remifentanil infusion [yes or no], and midazolam bolus [yes or no]) were assessed in univariate regression analysis and, if significant, further multivariate analyses including other potential confounders were performed. Potential confounders included age, gender, American Society of Anesthesiologists score, body mass index, smoking history, history of cardiac disease (including hypertension), history of pulmonary disease, history of neurological disease, history of psychiatric diseases, preoperative dose and duration on levodopa, preoperative dosage of levodopa, and mean duration of PD.

We also summarized the types of sedative regimens used and explored if a particular sedative regimen had an impact on surgical outcome and on intraoperative and postoperative complications. The type of sedative regimen (the combination of drugs used) was important to analyze because sedatives are usually given in combination, as boluses or as infusions (e.g. concomitant propofol and remifentanil infusions). The choice of drug combinations was not standardized (left to the discretion of the attending anesthesiologist), thus allowing for possible bias.

\section{RESULTS}

We analyzed data from 121 patients (45 males, 76 females) of 124 consecutive PD patients. Three patients were excluded because of either lost to follow-up or incomplete primary outcome data (Figure 1). The patients' demographics, premorbid state, PD history, and surgical history are summarized in Table 1 . The mean age was $60.3 \pm 8.8$ years. Most of the DBS patients had long-standing medical refractory $\mathrm{PD}$ with a mean duration of $\mathrm{PD}$ of $9.71 \pm 3.1$ years and were on a high daily dose of levodopa or equivalent $(1069.6 \pm 516.4 \mathrm{mg})$ preoperatively. The majority of the patients (97.5\%) had bilateral DBS electrodes implanted, with the most common target being the subthalamic nuclei (95\% of cases).

\section{Summary of Overall Outcomes}

A total of 116 patients successfully completed the procedure and were followed up in the neurology clinic 6 months postoperatively (average, $188.9 \pm 12.5$ days). We found that, at 6 months postoperatively, there was a $46.9 \pm 4.0 \%$ decrease in LEDD and $17.6 \pm 3.3 \%$ improvement in motor symptoms (when comparing postoperative stimulator-on, medication-off state with the preoperative medication-on state) at 6 months. A total of 116 $(95.9 \%)$ of 121 patients successfully completed the DBS procedure; five $(4.1 \%)$ failed to complete the procedure. The average durations of stage 1 procedure and MER were $393 \pm 54.1$ and $135.5 \pm 30.7$ minutes, respectively. The overall average length of hospital stay was $3.4 \pm 1$ day (Table 2).

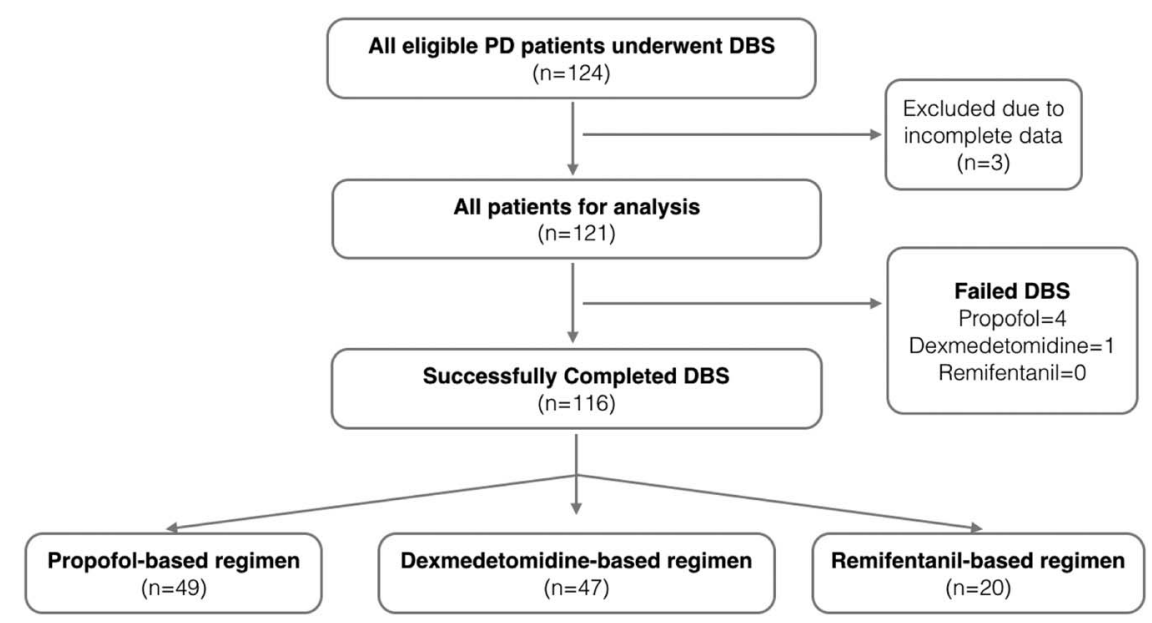

Figure 1: Study flow diagram. $D B S=$ deep brain stimulation; $P D=$ Parkinson's disease. 


\section{Table 1: Demographic data of study patients}

\begin{tabular}{|c|c|c|c|c|c|}
\hline & $\begin{array}{c}\text { Total } \\
(n=121)\end{array}$ & $\begin{array}{l}\text { Propofol-based } \\
\text { regimen }(n=53)\end{array}$ & $\begin{array}{l}\text { Dexmedetomidine-based } \\
\text { regimen }(n=48)\end{array}$ & $\begin{array}{l}\text { Remifentanil-based } \\
\text { regimen }(n=20)\end{array}$ & $\begin{array}{l}\text { Statistical test } \\
\text { (p value) }\end{array}$ \\
\hline \multicolumn{6}{|l|}{ Demographics } \\
\hline Age, years & $60.3 \pm 8.8$ & $59.7 \pm 9.2$ & $59.4 \pm 8.2$ & $64 \pm 8.6$ & 0.099 \\
\hline Gender (F/M) & $45 / 76$ & $24 / 28$ & $16 / 33$ & $5 / 15$ & 0.174 \\
\hline ASA II/III/IV & $8 / 108 / 5$ & $6 / 44 / 2$ & $2 / 44 / 3$ & $0 / 20 / 0$ & 0.249 \\
\hline BMI, $\mathrm{kg} / \mathrm{m}^{2}$ & $30.0 \pm 4.3$ & $28.9 \pm 3.9$ & $30.6 \pm 4.1$ & $31.0 \pm 5.3$ & 0.021 \\
\hline Smoker, no/yes & $106 / 15$ & $47 / 5$ & $41 / 8$ & $18 / 2$ & 0.556 \\
\hline Cardiac disease (hypertension), no/yes & $105 / 16$ & $42 / 10$ & $44 / 5$ & $19 / 1$ & 0.202 \\
\hline Pulmonary disease, no/yes & $110 / 11$ & $50 / 2$ & $44 / 5$ & $16 / 4$ & 0.096 \\
\hline $\begin{array}{l}\text { Other neurological diseases (stroke, } \\
\text { seizures), no/yes }\end{array}$ & $119 / 2$ & $51 / 1$ & $48 / 1$ & $20 / 0$ & 0.817 \\
\hline Psychiatric disease, no/yes & $112 / 9$ & $48 / 4$ & $46 / 3$ & $18 / 2$ & 0.289 \\
\hline Drug abuse history, no/yes & $121 / 0$ & 0 & 0 & 0 & N/A \\
\hline \multicolumn{6}{|l|}{ Parkinson disease and surgical data } \\
\hline Duration of levodopa treatment, year & $9.61 \pm 2.9$ & $9.4 \pm 3.0$ & $9.6 \pm 3.0$ & $10.2 \pm 2.5$ & 0.583 \\
\hline $\begin{array}{l}\text { Preoperative dose of levodopa or } \\
\text { equivalent, mg/day }\end{array}$ & $1069.6 \pm 516.4$ & $1135.6 \pm 604.7$ & $1058.2 \pm 463.7$ & $926.3 \pm 356.7$ & 0.514 \\
\hline Preoperative simplified UPDRS-III score & $21.7 \pm 5.4$ & $21.6 \pm 5.0$ & $21.7 \pm 5.0$ & $21.6 \pm 7.2$ & 0.9 \\
\hline $\begin{array}{l}\text { Mean duration of preoperative management } \\
\text { by neurologist, year }\end{array}$ & $2.2 \pm 0.81$ & $2.1 \pm 0.82$ & $2.3 \pm 0.8$ & $2.0 \pm 0.9$ & 0.151 \\
\hline Mean duration of disease since onset, year & $9.71 \pm 3.1$ & $9.6 \pm 3.1$ & $9.5 \pm 3.2$ & $10.5 \pm 2.7$ & 0.45 \\
\hline Laterality of target, L/R/both & $3 / 0 / 118$ & $3 / 0 / 49$ & $0 / 0 / 49$ & $0 / 0 / 20$ & NA \\
\hline Target nucleus of localization, STN/non-STN & $115 / 6$ & $48 / 4$ & $47 / 2$ & $20 / 0$ & 0.378 \\
\hline
\end{tabular}

Abbreviations: ASA = American Society of Anesthesiologists score; $\mathrm{BMI}=$ body mass index; $\mathrm{F}=$ females; $\mathrm{M}=$ males.

\section{Primary Analysis}

In the univariate regression analyses, we failed to identify any association between individual sedative agents (e.g. propofol, dexmedetomidine, remifentanil, and midazolam) and the UPDRSIII score and LEDD reduction at 6 months postoperatively (Table 3). There was also no statistically significant association between the use of individual agents and the success of DBS implantation, duration of MER, and duration of stage 1 procedure (Table 3). No multivariate regression analyses were performed.

Further regression analysis found that there was no statistically significant association between the use of individual sedative agents and the procedure success rates (Table 3 ). In those patients in which bilateral DBS procedures were successfully completed, there was no statistical significant association between use of individual sedative agents and the duration of the procedure or the duration of MER.

\section{Secondary Analysis: Anesthetic Regimen}

We identified that three sedative regimens were commonly used in our institute: propofol, dexmedetomidine, and remifentanil-based (Table 4). Propofol and remifentanil were available in our institute for the entire study period, whereas dexmedetomidine was available after 2008. Despite the retrospective nature of this study, the sedative regimen (loading and maintenance dose) within each group was consistent over the study period, reflecting consistent anesthetic practices in a small group of neuroanesthesiologists at our institute.
In the propofol-based regimen, all cases received an infusion of propofol at 40 to $50 \mathrm{mg} / \mathrm{kg} / \mathrm{min}$ (without loading dose). A total of $58.4 \%$ of patients in the propofol-based group received a supplementary infusion of remifentanil, and $20.8 \%$ of patients received low-dose midazolam $(0.5-2 \mathrm{mg})$ at the start of the surgery (Table 4).

In the dexmedetomidine-based group, the most commonly used regimen was an initial bolus of dexmedetomidine $(0.3-0.7 \mathrm{mcg} / \mathrm{kg})$ followed by dexmedetomidine infusion at 0.25 to $0.55 \mathrm{mcg} / \mathrm{kg} / \mathrm{h}$. A total of $22.9 \%$ of patients in this group received a supplementary bolus of propofol at the start of surgery, and $19.1 \%$ of patients received bolus of midazolam $(0.5-2 \mathrm{mg})$ at the start of surgery (Table 4).

In the remifentanil-based group, all cases received an infusion of remifentanil at 0.02 to $0.04 \mathrm{mcg} / \mathrm{kg} / \mathrm{min}$. Thirty-one percent of patients in the remifentanil-based group received low-dose midazolam (0.5-2 mg) at the start of surgery (Table 4). We found inadequate documentation in the anesthetic records as to exact timing when drug infusions were stopped before MER. However, because our surgeons usually request that all sedation be stopped 20 to 30 minutes before MER, we presumed that this practice was applied to all patients.

\section{Outcomes in Three Sedative Regimens}

There were no statistical differences in demographic, preoperative medical problems, and preoperative PD severity among three anesthetic groups, except the body-mass index of patients were slightly higher in the remifentanil group (Table 1). There were no differences of levodopa dose reduction $(p=0.537)$ and 


\section{Table 2: Outcomes of DBS procedure}

\begin{tabular}{|c|c|c|c|c|c|}
\hline & $\begin{array}{c}\text { Total } \\
(n=116)\end{array}$ & $\begin{array}{l}\text { Propofol-based regimen } \\
\qquad(\mathrm{n}=49)^{*}\end{array}$ & $\begin{array}{l}\text { Dexmedetomidine- } \\
\text { based regimen } \\
(n=47)\end{array}$ & $\begin{array}{l}\text { Remifentanil- } \\
\text { based regimen } \\
\quad(\mathbf{n}=\mathbf{2 0})\end{array}$ & $\begin{array}{l}\text { Statistical test } \\
\quad \text { (p value) }\end{array}$ \\
\hline $\begin{array}{l}\% \text { of successful completion rates of the DBS procedure (number } \\
\text { of successful patients/total patients) }\end{array}$ & $95.9(116 / 121)$ & $92.5(49 / 53)$ & $98.0(47 / 48)$ & $100(20 / 20)$ & 0.545 \\
\hline 6-month postoperative assessment (days after the procedure) & $188.9 \pm 12.5$ & $189.1 \pm 13.0$ & $188.4 \pm 11.5$ & $189.3 \pm 14.1$ & 0.844 \\
\hline $\begin{array}{l}\% \text { of improvement of UPDRS-III score (stimulation-on, } \\
\text { medication-off) }\end{array}$ & $17.6 \pm 3.3$ & $17.6 \pm 4.0$ & $18.2 \pm 2.4$ & $16.3 \pm 3.5$ & 0.74 \\
\hline LEDD reduction $(\%)$ & $46.9 \pm 4.0$ & $42.7 \pm 4.0$ & $51.9 \pm 3.4$ & $45.7 \pm 5.3$ & 0.537 \\
\hline Duration of stage 1 procedure for bilateral DBS, minutes & $393.5 \pm 54.1$ & $391.5 \pm 54.9$ (46 patients) & $396.6 \pm 56.9$ & $391.0 \pm 47.2$ & 0.905 \\
\hline Duration of MER for bilateral DBS, minutes & $135.5 \pm 30.7$ & $134.5 \pm 29.9$ (46 patients) & $139.5 \pm 29.1$ & $128.7 \pm 36.3$ & 0.356 \\
\hline Duration of hospital stay, days & $3.4 \pm 1.0$ & $3.4 \pm 0.6$ & $3.2 \pm 0.6$ & $3.9 \pm 1.8$ & 0.112 \\
\hline
\end{tabular}

*Three patients in the propofol group only had unilateral DBS implantation with a mean total duration of stage 1 procedure of 251.6 minutes and a mean total duration of MER of 81.3 minutes.

motor symptoms improvement $(\mathrm{p}=0.74)$ among the three sedative regimens (Table 4), although the propofol group experienced more failure cases (four cases) compared with the dexmedetomidine group (one case) and the remifentanil (no cases) group. Four patients in the propofol group had their procedures aborted: two from anesthesia-related complications. One patient developed severe agitation, flailing his arms and legs during electrode placement; additional propofol was given resulting in acute airway obstruction that required immediate packing of surgical site and removal of Leksell frames for airway management). The other patient developed tachyarrhythmia with ST segment changes during electrode placement; additional propofol was given, resulting in hypoxia. The remaining two cases were prematurely terminated because of surgical complications: serious electrode misplacement (suspected from frame displacement), with the surgeon deciding that it was not safe to proceed in one, and thalamic hemorrhage occurred in the other (no specific cause was identified). In the dexmedetomidine group, one patient developed severe dystonia and hand spasm leading to termination of the procedure. For those patients who had successful bilateral DBS procedures, there were no statistical significances between the anesthetic groups and the durations of the procedure $(p=0.905)$ and of $\operatorname{MER}(\mathrm{p}=0.356)$.

\section{Complications}

Intraoperative complications were common but mostly minor (except for the five cases that could not have their surgeries completed). The overall and subgroup complication rates are listed in Table 5. There were no statistical differences in complications between groups, except for intraoperative bradycardia and hypertension. The dexmedetomidine group was found to have more intraoperative bradycardic events (11 patients) when compared with the propofol (one patient) and remifentanil (one patient) groups. Intraoperative hypertension was the most common intraoperative complication (37.2\%). Antihypertensive agents were required in $19 \%$ of cases ( 23 of 121 patients). There was no statistical significance between groups in the incidence of hypertensive events $(\mathrm{p}=0.66)$ and the need for labetalol (first-line antihypertensive agent) $(\mathrm{p}=0.15)$. However, the need for a second antihypertensive agent (hydralazine) was significantly higher in the propofol group. Only one patient required a second antihypertensive agent (hydralazine) in the dexmedetomidine group, whereas, nine of 11 patients in the propofol group required a second antihypertensive (hydralazine) to stabilize blood pressure. There was no statistical significance between groups with underlying cardiac disease (including hypertension), but we were unable to confirm if all patients received their usual antihypertensive medications on the morning of surgery.

Long-term postoperative complications (postoperative day 1 to 6 months) were similar between groups. All patients survived at 6 months postoperatively (Table 5).

\section{DISCUSSION}

Our study demonstrated that the use of individual sedative agents in DBS for PD patients did not affect the success rate of DBS or 6-month postoperative surgical outcomes using MER and macrostimulation techniques. In addition, there was no effect on

Table 3: Results of regression analyses

\begin{tabular}{|c|c|c|c|c|}
\hline Outcomes & Propofol infusion used & Dexmedetomidine infusion used & Remifentanil infusion used & Midazolam used \\
\hline$\%$ Reduction in UPDRS-III score & OR, $0.33 ; p=0.54$ & $\mathrm{OR},-0.11 ; \mathrm{p}=0.86$ & $\mathrm{OR},-0.02 ; \mathrm{p}=0.78$ & OR, $-0.01 ; p=0.83$ \\
\hline$\%$ LEDD reduction & $\mathrm{OR},-0.08 ; \mathrm{p}=0.93$ & OR, $0.06 ; p=0.56$ & $\mathrm{OR},-0.08 ; \mathrm{p}=0.39$ & $\mathrm{OR},-0.02 ; \mathrm{p}=0.85$ \\
\hline Total stage 1 procedural time & $\mathrm{OR},-2.36 ; \mathrm{p}=0.88$ & OR, $0.26 ; p=0.99$ & $\mathrm{OR},-2.17 ; \mathrm{p}=0.89$ & OR, $21.0 ; p=0.17$ \\
\hline Total duration of MER & OR, $-2.76 ; p=0.63$ & OR, $9.05 ; \mathrm{p}=0.12$ & $\mathrm{OR},-1.16 ; \mathrm{p}=0.84$ & OR, $1.41 ; \mathrm{p}=0.81$ \\
\hline Successful completion of DBS & $\mathrm{OR},-0.85 ; \mathrm{p}=0.34$ & OR, $-0.44 ; p=0.60$ & $\mathrm{OR},-0.85 ; \mathrm{p}=0.34$ & OR, $0.30 ; p=0.75$ \\
\hline
\end{tabular}

Abbreviations: $\mathrm{OR}=$ odds ratio. 
Table 4: Anesthetic management in the three sedative regimen groups

\begin{tabular}{|c|c|c|c|c|}
\hline & Propofol-based regimen $(n=53)$ & $\begin{array}{l}\text { Dexmedetomidine-based regimen } \\
\qquad(\mathrm{n}=48)\end{array}$ & Remifentanil-based regimen $(n=20)$ & $\begin{array}{l}\text { Statistical test } \\
\quad(p \text { value })\end{array}$ \\
\hline Loading dose & NA & $0.51 \pm 0.42 \mathrm{mcg} / \mathrm{kg}$ & NA & NA \\
\hline $\begin{array}{l}\text { Maintenance } \\
\text { dose }\end{array}$ & $43.8 \pm 15.4 \mathrm{mcg} / \mathrm{kg} / \mathrm{min}$ & $0.41 \pm 0.15 \mathrm{mcg} / \mathrm{kg} / \mathrm{h}$ & $0.03 \pm 0.001 \mathrm{mcg} / \mathrm{kg} / \mathrm{min}$ & NA \\
\hline Total dose & $824.5 \pm 274.9 \mathrm{mcg}$ & $149.2 \pm 65.7 \mathrm{mcg}$ & $854.11 \pm 397.6 \mathrm{mcg}$ & NA \\
\hline $\begin{array}{l}\text { Midazolam, } \\
\text { mg }\end{array}$ & $0.76 \pm 1.0(11 \mathrm{pts})$ & $0.35 \pm 1.0(9$ patients $)$ & $2.2 \pm 2.5$ (18 patients) & 0.000 \\
\hline $\begin{array}{l}\text { Total fentanyl, } \\
\text { mg }\end{array}$ & $34.4 \pm 92.0(11 \mathrm{pts})$ & $11.4 \pm 27.9$ (10 patients) & $17.9 \pm 54.1$ (4 patients) & 0.912 \\
\hline $\begin{array}{l}\text { Total labetalol, } \\
\text { mg }\end{array}$ & $13.7 \pm 31.4(11 \mathrm{pts})$ & $2.8 \pm 10.7$ ( 7 patients $)$ & $8.2 \pm 26.7$ ( 5 patients $)$ & 0.15 \\
\hline \multirow{2}{*}{$\begin{array}{l}\text { Total } \\
\text { hydralazine, } \\
\text { mg }\end{array}$} & $3.7 \pm 8.6(9 \mathrm{pts})$ & $0.2 \pm 1.2(1$ patient $)$ & $2.5 \pm 7.0(3$ patients $)$ & 0.033 \\
\hline & $\begin{array}{l}\text { Supplementary remifentanil infusion was used in } \\
31 \text { patients; mean maintenance dose, } \\
0.02 \mathrm{mcg} / \mathrm{kg} / \mathrm{min} \text {; mean total dose, } 377 \mathrm{mcg}\end{array}$ & $\begin{array}{l}\text { Bolus propofol with mean total dose of } \\
67.7 \mathrm{mg} \text { (11 patients) }\end{array}$ & $\begin{array}{l}\text { Bolus propofol with mean total dose of } \\
20 \mathrm{mg} \text { (1 patient) }\end{array}$ & \\
\hline
\end{tabular}

procedural time or MER time (using the five microelectrodes simultaneous recording technique). We did not find major differences in surgical outcomes, procedural success rates, procedural time and MER, and perioperative complications among the three commonly used sedative regimens. Although not statistically significant, propofol were used in four of five patients $(80 \%)$ who failed the procedure, in which two patients were anesthesia-related and two were surgery-related. The exception was that intraoperative bradycardia was more commonly encountered with the use of the dexmedetomidine-based regimen,

Table 5: Intraoperative complications and postoperative complications from postoperative day 1 to 6 months

\begin{tabular}{|c|c|c|c|c|c|}
\hline & $\begin{array}{l}\text { Total events } \\
(n=121)\end{array}$ & $\begin{array}{l}\text { Propofol-based } \\
\text { regimen }(n=53)\end{array}$ & $\begin{array}{l}\text { Dexmedetomidine-based } \\
\text { regimen }(n=48)\end{array}$ & $\begin{array}{l}\text { Remifentanil-based } \\
\text { regimen }(n=20)\end{array}$ & $\begin{array}{l}\text { Statistical test } \\
\quad \text { (p value) }\end{array}$ \\
\hline \multicolumn{6}{|l|}{ Anesthesia-related intraoperative complications } \\
\hline Agitation or confusion & 7 & 1 & 3 & 2 & 0.24 \\
\hline Hypertension (SBP > 160 mmHg) & 45 & 19 & 15 & 8 & 0.66 \\
\hline Bradycardia (HR <60 beats/min) & 12 & 1 & 11 & 1 & 0.034 \\
\hline Airway obstruction & 4 & 2 & 2 & 0 & 0.56 \\
\hline Desaturation $\left(\mathrm{SpO}_{2}<90 \%\right)$ & 3 & 3 & 2 & 1 & 0.48 \\
\hline Severe headache & 2 & 2 & 2 & 0 & 0.65 \\
\hline Nausea/vomiting & 3 & 1 & 1 & 1 & 0.75 \\
\hline \multicolumn{6}{|l|}{ Surgical-related intraoperative complication } \\
\hline Electrode misplacement & 1 & 1 & 0 & 0 & 0.59 \\
\hline Intracranial hemorrhage & 1 & 1 & 0 & 0 & 0.59 \\
\hline Seizure & 0 & 0 & 0 & 0 & NA \\
\hline Akinetic mutism & 0 & 0 & 0 & 0 & NA \\
\hline \multicolumn{6}{|l|}{ Postoperative complications } \\
\hline $\begin{array}{l}\text { Cognitive/psychiatric complications (memory } \\
\text { decline, depression, anxiety, mood) }\end{array}$ & 3 & 1 & 1 & 1 & 0.76 \\
\hline $\begin{array}{l}\text { Procedural-related complications (e.g. lead fracture, } \\
\text { migration, battery failure) }\end{array}$ & 0 & 0 & 0 & 0 & NA \\
\hline Physical complications (hemorrhage, infection) & 4 & 2 & 2 & 0 & 0.61 \\
\hline $\begin{array}{l}\text { Transient/permanent side effects (dysarthria, gait } \\
\text { disorder, dysequilibrium) }\end{array}$ & 6 & 2 & 2 & 2 & 0.56 \\
\hline
\end{tabular}

Abbreviations: $\mathrm{HR}$, heart rate; $\mathrm{SBP}$, systolic blood pressure; $\mathrm{SpO}_{2}$, oxygen saturation. 
and the need for a second antihypertensive agent (hydralazine) to reduce blood pressure was more common in the propofol-based regimen.

\section{Strength and Limitation}

The major limitation of this study is its retrospective design, which may incur selection and information bias. Selection bias is caused by nonrandomized selection of study subjects or groups that result in an unrepresentative population sample for analysis. The choice of sedative agents for DBS in our institute was mainly driven by anesthesiologist preference. We have a small neuroanesthesia team, and each neuroanesthesiologist showed a consistent choice and dosage of the sedative agent in DBS over the study period. Because the allocation of attending anesthesiologist to patient (with the preferred sedative agent) is random, we feel that the resulting allocation of the sedative agent was random. Therefore, we observed three distinct sedative regimens used during DBS with similar baseline demographics and the perceived risk of selection bias was not high. Another limitation is that our findings were based on the MER using a five-microelectrode simultaneous recording technique; the impact of sedatives on alternate MER technique such as sequential trajectory cannot be extrapolated from this study.

The major strength in this study is that we took a different approach to examining the various sedative effects on surgical outcomes in PD patients in a pragmatic setting, unlike previous studies that focused on the pharmacology of sedative agents on deep brain nuclei. In addition, all data were adequately retrieved. The data for LEDD were objectively documented in neurologists' notes and the UPDRS-III motor score of all patients was assessed by an independent neurologist; therefore, we would feel that the risk of information bias is low.

\section{Interpretation}

There are no studies that compare differing sedative agents during DBS surgery. The majority of published studies are observational and usually report the use of a single sedative agent. ${ }^{12-14}$ Propofol is reported to be the most frequently used sedative agents during DBS surgery. ${ }^{7,8} \mathrm{~A}$ case series of 16 patients showed that propofol infusion at $50 \mu \mathrm{g} / \mathrm{kg} / \mathrm{min}$ can significantly decrease STN neuronal background and spiking activity, ${ }^{12}$ although this suppressive effect is transient and all STN neuronal activity returned to normal shortly after cessation. There was also a report of altered pharmacodynamic properties of propofol in PD patients. ${ }^{16}$ In clinical practice, there have been concerns of either the residual suppressive effect of propofol on MER and possible effect on surgical outcome or in prolongation of procedural time while waiting for the drug to dissipate. However, there have been no studies examining for this effect.

We found that the use of propofol sedation did not affect surgical outcome, procedural success rate, procedural time, or MER. However, in four of five patients $(80 \%)$ in which the DBS procedure had to be aborted, propofol was the sedative agent used, and in two of the four patients, oversedation with propofol leading to acute airway obstruction and hypoxia was noted, reflecting the risks of oversedation in patients with a Leksell frame.

Some descriptive studies have reported the successful use of dexmedetomidine during DBS in PD patients. ${ }^{12,13}$ The benefits of dexmedetomidine include minimal suppressive effect on MER in low dose and a lower risk of respiratory depression. ${ }^{17} \mathrm{~A}$ retrospective study of 19 patients found that dexmedetomidine provided better patient satisfaction and reduced the use of intraoperative antihypertensives compared with no anesthetics during DBS (monitored anesthetic care), ${ }^{12}$ whereas the other retrospective study showed the addition of dexmedetomidine to propofol did not reduce the use of antihypertensives. ${ }^{18}$ Dexmedetomidine has become the sedative agent of choice in many institutes because of its perceived benefits over the other agents, ${ }^{7,19}$ although the evidence is limited and the number of patients in the studies are small.

High infusion rates of opioid while not suppressing deep brain nuclei activity can worsen muscle rigidity and cause respiratory depression. In our study, a remifentanil-based regimen was not associated with more airway obstruction or oxygen desaturation.

Hypertension can be associated with intracranial hemorrhage during electrode placement. It has been recommended that systolic blood pressure be kept below $140 \mathrm{mmHg}$ during DBS procedures. ${ }^{20}$ A study using a rodent model ${ }^{21}$ suggested that beta-blockers modulate GABA release in the STN via noradrenergic receptors. A recent case report of three patients ${ }^{22}$ reported that metoprolol induces reversible suppression on bursting activities of STN and reduces PD symptoms (rigidity), suggesting possible interaction during MER. In our study, 21(17\%) and $22(18 \%)$ patients required labetalol (a mixed alpha and beta blocker) and hydralazine for blood pressure control, respectively. The effect of labetalol or hydralazine on MER was not specifically studied, but in our experience, we did not see an effect of these agents on MER. Benzodiazepines can abolish the STN activities. In our study, one-third of all patients received a low dose of midazolam at the commencement of the DBS procedure, but we found no correlation between the use of midazolam and surgical outcomes.

Despite the limitations of a retrospective study, this study is by far the largest cohort (best available evidence) exploring the impact of sedative agents on the surgical outcomes of Parkinsonian patients who have undergone DBS. The electrophysiological activities of deep brain nucleus are highly affected by sedative agents, but it may be inappropriate to extrapolate that this will lead to poor surgical outcomes. We would advise caution in interpreting our results of not finding differences between sedative groups. Our results were achieved by a small group of experienced neuroanesthesiologists who were familiar with the pharmacological properties of their preferred agent and its usage (e.g. appropriately ceasing infusion 20-30 minutes before MER). We recommend that the choice of anesthetic agents should be dictated by the anesthesiologist according to patient factors (e.g. comorbidities), his/her experience with the agent and local practices. An experienced anaesthetist, open communication between neurosurgery and anaesthesia, and being mindful of the patients' health status and comorbidities likely contribute more to the outcomes and surgery success than which sedatives is used.

\section{CONCLUSION}

We found that using individual sedative agents (propofol, dexmedetomidine, remifentanil, and midazolam) had no impact on surgical outcomes at 6 months in PD patients who underwent successful DBS procedures using MER and macrostimulation techniques. Although not statistically significant, four of five 
aborted patients were on propofol; this fact dictates a careful surveillance from an experienced neuro-anesthesiologist who is familiar with the pharmacological properties of the preferred sedatives in DBS procedures. A prospective analysis of anesthesiaand surgical-related complications would help to further explore the other factors contributing to good or bad outcomes during DBS procedures.

\section{ACKNOWLEDGMENTS AND FUNDING}

None.

\section{Disclosures}

JC has the following disclosures: Lawson Health Research Institute; research award, Western University; department internal research awards, Western University. The remaining authors have nothing to disclose.

\section{Statement of Authorship}

JC, AR, and RAC helped design the study and prepare the manuscript. AP helped prepare the manuscript. JC, AR, and RAC approved the final manuscript. AR and RAC attest to the integrity of the original data and the analysis reported in this manuscript. JC is the archival author and attests to the integrity of the original data and the analysis reported in this manuscript.

\section{REFERENCES}

1. Benabid AL, Chabardes S, Mitrofanis J, Pollak P. Deep brain stimulation of the subthalamic nucleus for the treatment of Parkinson's disease. Lancet Neurol. 2009;8:67-81.

2. Deuschl G, Schade-Brittinger C, Krack P, Volkmann J, Schafer H, Botzel K, et al. A randomized trial of deep-brain stimulation for Parkinson's disease. N Engl J Med. 2006;355:896-908.

3. Kocabicak E, Temel Y. Deep brain stimulation of the subthalamic nucleus in Parkinson's disease: surgical technique, tips, tricks and complications. Clin Neurol Neurosurg. 2013;115:2318-23.

4. Raz A, Eimerl D, Zaidel A, Bergman H, Israel Z. Propofol decreases neuronal population spiking activity in the subthalamic nucleus of Parkinsonian patients. Anesth Analg. 2010;111:1285-9.

5. Krishna V, Elias G, Sammartino F, Basha D, King NK, Fasano A, et al. The effect of dexmedetomidine on the firing properties of STN neurons in Parkinson's disease. Eur J Neurosci. 2015; 42:2070-7.

6. Elias WJ, Durieux ME, Huss D, Frysinger RC. Dexmedetomidine and arousal affect subthalamic neurons. Mov Disord. 2008; 23:1317-20.

7. Venkatraghavan L, Luciano M, Manninen P. Review article: anesthetic management of patients undergoing deep brain stimulator insertion. Anesth Analg. 2010;110:1138-45.
8. Venkatraghavan L. Anesthesia for patients having deep brain stimulator implantation. Available at: https://www.uptodate.com/contents/ anesthesia-for-patients-having-deep-brain-stimulator-implantation.

9. Kalenka A, Schwarz A. Anaesthesia and Parkinson's disease: how to manage with new therapies? Curr Opin Anaesthesiol. 2009; 22:419-24.

10. Rezai AR KB, Gross RE, Vitek JL, Sharan AD, Limousin P, Benabid AL. Deep brain stimulation for Parkinson's disease: surgical issues. Mov Disord. 2006;21:s197-218.

11. Israel Z H-BS. Subthalamic stimulation for Parkinson's disease. Isr Med Assoc J. 2005;7:458-63.

12. Rozet I, Muangman S, Vavilala MS, Lee LA, Souter MJ, Domino $\mathrm{KJ}$, et al. Clinical experience with dexmedetomidine for implantation of deep brain stimulators in Parkinson's disease. Anesth Analg. 2006;103:1224-8.

13. Hippard HK, Watcha M, Stocco AJ, Curry D. Preservation of microelectrode recordings with non-GABAergic drugs during deep brain stimulator placement in children. J Neurosurg Pediatr. 2014;14:279-86.

14. Khatib R EZ, Rezai A, Cata JP, Boulis NM, John Doyle D, Schurigyn T, Farag E. Perioperative events during deep brain stimulation: the experience at Cleveland Clinic. J Neurosurg Anesthesiol. 2008;20:36-40.

15. Goetz CG, Tilley BC, Shaftman SR, Stebbins GT, Fahn S, Martinez-Martin P, et al. Movement Disorder Society-sponsored revision of the Unified Parkinson's Disease Rating Scale (MDS-UPDRS): scale presentation and clinimetric testing results. Mov Disord. 2008;23:2129-70.

16. Fábregas N RJ, Gambús PL, Valero R, Carrero E, Salvador L, NaldaFelipe MA, Trocóniz IF. Modeling of the sedative and airway obstruction effects of propofol in patients with Parkinson disease undergoing stereotactic surgery. Anesthesiology. 2002;97: 1378-86.

17. Sassi M, Zekaj E, Grotta A, Pollini A, Pellanda A, Borroni M, et al. Safety in the use of dexmedetomidine (precedex) for deep brain stimulation surgery: our experience in 23 randomized patients. Neuromodulation. 2013;16:401-6.

18. Rajan S, Deogaonkar M, Kaw R, Nada EM, Hernandez AV, Ebrahim Z, et al. Factors predicting incremental administration of antihypertensive boluses during deep brain stimulator placement for Parkinson's disease. J Clin Neurosci. 2014;21:1790-5.

19. Manninen PH, Venkatraghaven L. Stereotactic surgery, deep brain stimulation, brain biopsy, and gene therapies. In: Cottrell JE, Patel P, editors. Cottrell and Patel's neuroanesthesia. 6th ed. New York: Elsevier; 2017. p. 317-25.

20. Venkatraghavan L, Manninen P. Anesthesia for deep brain stimulation. Curr Anesthesiol Rep. 2016;6:233-43.

21. Belujon P, Bezard E, Taupignon A, Bioulac B, Benazzouz A. Noradrenergic modulation of subthalamic nucleus activity: behavioral and electrophysiological evidence in intact and 6hydroxydopamine-lesioned rats. J Neurosci. 2007;27:9595-606.

22. Coenen VA, Gielen FLH, Castro-Prado F, Rahman AA, Honey CR. Noradrenergic modulation of subthalamic nucleus activity in human: metoprolol reduces spiking activity in microelectrode recordings during deep brain stimulation surgery for Parkinson's disease. Acta Neurochir (Wien). 2008;150:757-62. 